\title{
PUBLIC MEDICAL SERVICES UNDER TITLE XIII OF THE NATIONAL HEALTH BILL*
}

\author{
David P. Caverst
}

If major changes in the organization of American medical services were to follow from the enactment of the National Health Bill ${ }^{1}$ in its present form, it would be principally by virtue of Title XIII which that bill proposes to add to the Social Security Act. ${ }^{2}$ The proposed Title XIII authorizes grants-in-aid to states for the purpose of enabling them to "extend and improve medical care (including all services and supplies necessary for the prevention, diagnosis, and treatment of illness and disability)."3 It is under this title that state measures establishing systems of compulsory health insurance might qualify for federal grants, and hence the title introduces what is assuredly the most controversial of the debated aspects of the national health program.

But, as the language quoted above makes obvious, Title XIII does not require the adoption of compulsory health insurance as a prerequisite to the grants it authorizes. On the contrary, it is couched in terms of unusual generality, terms which are suffciently broad to permit the qualification of a diversity of other measures designed to "extend and improve medical care." Most, and perhaps all, such other measures can be comprehended in the broad category of "public medical services," namely, medical services administered by governmental agencies and supported by taxation.

Proposed state legislation establishing compulsory health insurance systems which might qualify for grants under Title XIII is discussed in the succeeding article in this symposium. This note will deal briefly with problems to be considered in devising state public medical service legislation to qualify for grants under that title. Although health insurance legislation would constitute a more drastic departure from past American practice and hence the issues of policy which it raises may be graver than

\footnotetext{
- In the organization of this symposium, provision was made for an article on this topic by a leading authority in the field. Circumstances which precluded his contributing to the symposium arose at a time too late to permit the enlisting of another contributor. Rather than omit all consideration of this important subject, this note was composed by the editor who makes no claim to first-hand knowledge of the field or expertness in its special problems.

+ B.S. in Econ., r923, University of Pennsylvania; LL.B., 1926, Harvard University. Member of the New York Bar. Professor of Law, Duke University, since r93r. Editor, Law and Contemporary Problems.

${ }^{1}$ S. 1620, 76th Cong., Ist Sess. (1939).

2 The National. Health Bill is comprised of five sections amending existing titles of the Social Security Act or adding new titles to it. Citations to provisions of the Bill will refer to the title and section numbers of the Social Securty Act, as amended by the Bill, and not to the section numbers of the Bill itself.

\$rzor.
} 
those posed by laws extending public medical services, nevertheless the questions presented by public medical service legislation may be of greater immediate importance. It would not be surprising if the states proved much more hesitant to resort to health insurance than to avail themselves of federal subsidies to augment services which, in greater or less degree, they are already providing. It is quite conceivable that there would develop systems of health insurance providing for certain employed groups of the population while public medical services were relied upon to assure care for the rest of those in need. Still another possible alternative is that the maćhinery of health insurance would be utilized to provide medical care to lowincome and indigent persons for whom the state would make contributions. ${ }^{4}$

\section{I}

Any consideration of the establishment of plans for public medical services under Title XIII requires discussion of the situation existing currently with respect to such services in the states as well as the specifications laid down by that title for the qualification of state plans for grants. Whatever plans may be developed under Title XIII, they will, of necessity, be influenced by the past and current experience of the states in the administration of tax-supported medical services.

This experience is not the product merely of the depression years. It is the outgrowth of state and local governmental activity in a number of related fields operating over a long period of time. Within the compass of this note, that experience can be sketched in only the briefest fashion. ${ }^{5}$

The English "poor law" of Elizabethan origin was the precedent for the assumption of legal responsibility for the medical care of the indigent by the American colonies and subsequently by the states. The responsibility fell upon the local unit of government, county, township, or municipality, and it was discharged as a rule in niggardly fashion. Often services were rendered by the physician who had succeeded in underbidding his competitors. Until hospitals gradually developed, it was the poorhouse which provided such institutional care as was afforded.

The development of the governmental hospital represented a step forward in the quality of public medical service, but the assumption of responsibility for hospitalization by government was not general. The non-governmental hospital, supported by charity, was relied upon to a considerable degree for general hospital service, whereas hospitals for tuberculosis, mental diseases, and contagious diseases were provided chiefly by government.

A third line of public medical service began with the development of public health services which were concerned at the outset primarily with preventive measures directed not toward the individual but toward the community in general. Responsibility for sanitation, for the prevention and control of communicable diseases, and for public health education fell under the jurisdiction of what might be termed

"Provisions to this end are found in the "model" bill of the American Ass'n for Social Sccurity. Sce Reed, Legislative Proposals for Compulsory Health Insurance, infra, p. 632.

${ }^{3}$ The development and present forms of tax-supported medical care in the United.States are surveyed in Davis, Public Medicai Services. (1937). 
the "old-line" public health service. Gradually, however, the scope of the service's activities have been extending into the area of service to the individual. Thus, the maintenance of maternity clinics, the care of crippled children, the correction of certain ailments among school children likely to retard their educational progress, and; especially in recent years, venereal disease clinics have become a public responsibility.

Supplementing these varied public medical services in filling the needs of those not in a position to purchase medical care have, of course, been the private practitioners and the non-governmental hospitals. The former have performed a very considerable volume of gratuitous service; the latter, especially in their out-patient clinics, have also assumed a substantial share of the load.

The combined operation of these various agencies sufficed, prior to the depression, to prevent the plight of those forced to rely upon them from becoming so serious a problem as to compel more systematic provision for their needs. The load was not unduly heavy either on the local taxpayer or on the private physician and hospital. It was the onset of the depression which forced consideration of the weaknesses and inadequacies of the system. As relief loads mounted, tax receipts fell, and physicians' and hospitals' incomes diminished, while the demands for gratuitous services increased, a crisis was created in many communities and over widespread areas.

With the organization of the Federal Emergency Relief Administration came an effort to cope with this problem through the use of federal funds. Rules and Regulations No. 7 of FERA, declaring that "The conservation of the public health is a primary function of a government," laid the basis for an extensive program of medical aid administered in connection with federal unemployment relief.

This regulation established certain broad principles under which aid was to be administered. Responsibility for authorizing care was vested in the relief officials, free choice of physicians (among those willing to provide services under a reduced fee schedule) was to be maintained, no provision was to be made for hospital facilities which were to be provided as previously. The amount of service which could be rendered under a single authorization was closely restricted.

This regulation was issued in July, I933. A study of its operation, ${ }^{6}$ completed in June, 1934, indicated that 29 states were operating "successfully" along the lines it laid down. It seems clear that the degree of success attained varied considerably among those states and among communities within them, and also that success was in considerable measure relative to the conditions antedating the regulation.

With the extinction of FERA came the end of federal contribution to relief medical services, but the need for such services persisted. The plans set up under Regulation No. 7 have in some instances been maintained, but there seems to have been a general tendency to depart from the free-choice-of-physician principle in order to achieve the greater economies possible under salaried doctors or panels of limited size.

- Leuck, Medical Care for the Unemployed and Their Familes under the Plan of the Federal. Emergency Relief Administration (Am. Pub. Welfare Ass'n, i934). 
II

Unfortunate for any effort to depict the situation as it now exists is the fact that comprehensive information is simply non-existent. Certain aspects of public medical services, hospitalization in state institutions, for example, are covered by relatively adequate statistics, but for most of the governmental activities only a vast amount of research would reveal the extent of service performed, its cost, its quality, and the legal powers and duties of those administering it.

A survey undertaken by the American Public Welfare Association summarized in the June 1938 report of its Committee on Medical Care ${ }^{7}$ is perhaps as good a source as any of conditions prevailing in the nation. Some of the principal findings embodied in this report may be briefly summarized ${ }^{8}$ as follows:

(I) As to the administration of public medical services, a veritable hodge-podge is revealed on both state and local levels. Roughly, responsibility is divided between departments of health and welfare, with special bodies in many cases charged with the administration of special institutional services. Not only does the division of responsibility follow no distinct pattern among the various states but the jurisdictional lines between the bodies within a single state are frequently blurred or overlapping. Still worse than the duplications are the gaps in authority which are often to be found. Efforts at coordination are rare and of such efforts many are relatively unsuccessful.

(2) Failure to utilize professional advice and supervision is common, even where authorized. Too often the services are dependent upon the views of a lay body, such as a board of county commissioners, charged with many other duties and often inspired chiefly by a desire to keep down expenditures.

(3) Intelligent planning and budgeting is impeded by the absence of adequate medical and financial statistics. Helpful comparison of such data as do exist is prevented by lack of standardization of statistical methods.

(4) On the vitally important problem of eligibility for medical care, no uniformity is to be found. Some jurisdictions provide only for those who are unable to support themselves when well. Other jurisdictions provide for care where recipients are found by financial investigation to be unable to acquire the services needed, although otherwise self-supporting. Still others provide for this group only in special "emergency" situations. "Pauper's oaths" and "means tests" are frequently employed. Some jurisdictions require patients to grant liens on their assets, including insurance, to secure future payment for services.

(5) Hospital service has provided problems where the government hospitals are non-existent or inadequate to carry the load. Payment is made to the non-governmental hospitals for service to indigent patients, but the basis for the payment, the

7 The Committee's report was based on replies to questionnaires from wcifare officials in 27 states and 54 cities and counties of over 100,000 population, including all parts of the country. In addition 36 localities in I7 states and Canada were covered by field trips. The survey was directed by Gertrude Sturges, M.D., consultant on medical care to the Association.

${ }^{8}$ In stating in very brief compass what I believe to be the gist of findings which extend over 35 pages, I may have been guilty of some over- or under-emphasis. 
problem of controlling the length of stay, and the assurance of proper standards of care are sources of widespread difficulties. In some communities, unlicensed "nursing homes" are used to supplement hospital facilities, and public homes for the aged have been converted to institutions for the care of the sick.

(6) The physician's service is supplied either on the principle of free choice of physician operative through the device of a panel of physicians or by the employment of part- or full-time physicians on salary. Experience with neither system seems generally to have been satisfactory. Panel practice has proved more expensive and the work tends to gravitate to the hands of the least competent physicians. Low salaries, heavy case loads, and little opportunity for advancement result as a rule in an unsatisfactory class of salaried physician. In neither arrangement is adequate supervision generally provided, often none at all.

(7) Where dental services are provided, the tendency is to restrict the services sharply, usually to the relief of pain and the correction of conditions affecting employability. In this field the problem of panel versus salaried personnel is again encountered.

(8) Bedside nursing service is generally insufficient, often non-existent. Moreover, there seems to be a tendency not to utilize to the full such services as may be available. There is evidence of yielding to the temptation to conserve funds for physicians' services by failing to employ nursing services.

(9) Control of drug costs and methods of limiting the use of drugs are squrces of difficulty. Prosthetic appliances-glasses, braces, and the like-are often given only when necessary to render the client employable.

This summarization of the report has excluded the brighter spots which occur in it. Yet the inclusion of the relatively few instances of successful administration which are reported would not materially relieve the darkness of the picture. Indeed, the exclusion of specific instances of maladministration in the summary probably more than compensates for the former omission. Yet certainly there exist in the nation many communities where the level of public medical service is on a plane distinctly above that described in the report. The report demonstrates an imperative need for reform, but it does not depict a hopeless condition.

\section{III}

With this background, consider what measures must be taken if federal aid is to be obtained under Title XIII as proposed in the National Health Bill. The state plan must, as has been seen, have for its purpose the extension and improvement of medical care. However, this requirement is subject to a qualifying clause: "as far as practicable under the conditions in such State, especially in rural areas and among individuals suffering from severe economic distress." Moreover, the major purpose of the plan is supplemented by the further purpose of enabling states "to develop more effective measures for carrying out the purposes of the title including the training of personnel."10

\footnotetext{
¡rzor.

${ }^{10} \mathrm{Ibid}$.
} 
At the outset uncertainty is encountered as to the content of the term "medical care." This is sufficiently broad to include virtually all types of public medical services which are directed toward the individual. Title XIII does not forbid the formulation of plans defining "medical care" thus broadly. Yet it is evident that the title was designed to assure improvement in the treatment of acute disease and chronic ailments other than those for which relatively satisfactory programs have already been or are being developed. Further, it seeks to discourage the development of "medical care" programs overlapping programs provided for in other titles of the Bill. The means to these ends is a provision in the section ${ }^{11}$ prescribing the method of computing the federal matching grant. This provides that state expenditures "for the care, in hospitals, institutions and other organized facilities, of cases of mental disease, mental defectiveness, epilepsy and tuberculosis" shall not be counted, nor shall sums "included in any other State plan submitted for grants under this or any other Act of Congress." Hence to achieve a maximum grant under Title XIII the state medical care plan must not extend to these fields of public medical service.

Section ${ }_{3} 303$ (a) prescribes the requirements which must be met by state plans to secure approval by the Social Security Board as eligible for federal grants. These will be listed with brief comment.

Clause (I) requires "financial participation by the State." The construction of comparable language in the Social Security Act makes clear that the state's participation may be through the medium of funds provided by its political subdivisions. The matching requirements will normally set the limits of state financial participation.

Clause (2) requires that the program be statewide or at least that the plan provide for the extension of the program so that coverage will be statewide by 1945. A question which might be raised by this provision is whether the plan must operate uniformly throughout the state. Social Security Board rulings on state old-age assistance plans indicate that this question may be answered in the negative. In view of the wide disparity in the needs of rural and urban areas, flexibility is highly desirable.

Clause (3) provides that the plan must be administered by the state health agency or by another state agency, but, in the latter event, the plan must provide "for cooperation and, when necessary, for working agreements between such agency and the state health agency." Provision is made to permit distribution of administrative functions among other agencies of the state and local governments if they are subject to the supervision of the state agency primarily charged with administration. It is evident that this provision permits each state to choose whether to vest administrative power in its health or welfare agencies. As has been pointed out, responsibility for public medical services is now quite generally divided between these agencies, and their jurisdictions are at times conflicting. The special demands of the depression have moreover produced many ad hoc emergency arrangements.

\footnotetext{
${ }^{11} \$ 1304$ (a). No effort will be made to discuss in this note the problems presented by the computation of the federal matching grant. These are discussed in Heer, A Study of the Formulae for Grants-in-Aid in the Wagner Bill, infra, p. 666.
} 
Opinion is divided within the membership of each of the two administrative groups as to the solution of the problem. There is marked tendency to regard the job as best suited to the other fellow. The explanation of this phenomenon may lie in the fact that the administration of medical care is extrinsic to the "old-line" work of each group. It represents a competitor for the funds available for those "old-line" duties and it calls for skills which "old-line" activities have not always developed.

No doubt the answer to this problem will vary from state to state. Administrative reorganization in some may be impeded by constitutional provisions prescribing departmental functions. In others political pressures may compel conformity to the contours of existing vested interests. In either case, it seems probable that the use of existing agencies could be made possible by the provision of supervisory controls linking the existing agencies to the central administrative body. However, attainment of optimum administrative organization would doubtless require rather thorough revamping of the existing system in most states.

Clause (4) requires provision of efficient methods of administration, especially a merit basis for personnel and "standards of medical and institutional care and of remuneration" therefor prescribed by the state agency after consultation with professional advisory committees. The civil service provision should operate to purge many state and local health administrations of political influences which have impaired their efficiency. Much progress was made toward achieving state merit systems under the Social Security Act even before its 1939 amendments granting direct power to the Board to condition grants on the adoption of merit systems. ${ }^{12}$ Where political appointees are firmly entrenched in local agencies, their duties can often be restricted to work which is not aided by federal grants.

The requirement that professional guidance be obtained as to standards of care and remuneration should diminish professional opposition to lay dictation as to such matters, without, however, compelling a surrender of ultimate state responsibility therefor.

Clause (5) requires that the plan "provide for an advisory council or councils" representing the professions, public and private agencies furnishing services under the plan, and informed members of the public. The requirement is designed both to correct the tendency, now prevalent, to fail to utilize professional advice and to assure that the advisory function is not deemed the exclusive prerogative of the professions. The requirement in clause (4) assures that the functions of at least the professional councils will be far from nominal.

Clause (6) requires the state administrative agency to make such reports as the Board may require. Not only would the operation of this clause end the existing

\footnotetext{
12 The Social Security Act, in the sections prescribing criteria for federal approval of state plans under the various titles, expressiy excluded methods of administration "relating to selection, tenure of office and compensation" from consideration by the federal agencies. The 1939 amendments permit the approving agency to require "personnel standards on a merit basis" but not to exercise authority over "the selcction, tenure of office, and compensation of any individual employed in accordance with" such standards. See, e.g., Social Security Act Amendments of 1939, Pub. No. 379, 76th Cong., Ist Sess. \$101(a) (5).
} 
shortage of data concerning public medical services, but it would also permit the standardization of the data made available so that comparison would be feasible.

Clause (7) requires provision for "cooperation and, when necessary, for working agreements," between the state agency and public agencies administering related services such as "welfare assistance, vocational rehabilitation, social insurance, workmen's compensation, labor, industrial hygiene, education, health or medical care." It seems fair to assume that time would be allowed for the perfection of the system of coordination envisaged by this clause, but ultimately it should operate to break down the present tendency toward compartmentation in what is essentially an integrated field.

Clause (8) requires that the state agency be vested with authority to issue necessary rules and regulations, an obvious necessity.

As has been seen, the title leaves a considerable range of choice of the states as to the nature of the medical care to be provided by their plan. Other important choices are also left open. Chief among these are determinations as to eligibility to receive care, the types of medical care to be provided, and the basis for utilizing physicians' and hospital services.

As to eligibility, the emphasis in the statement of the purpose of the grants upon aid to "individuals suffering from severe economic distress" suggests, if it does not require, that this group should be provided for if others are to be served, a consideration of concern in the planning of health insurance systems but scarcely of public medical services. Apparently, the states are free to insist, as some now do, upon pauper's oaths and means tests to assure that the recipients are not self-supporting. Yet the goal of extending medical care seems to anticipate serving at least the "medically indigent," a term which is susceptible of very liberal definition.

There is evidence of a growing belief that public medical service should be placed in the same plane as public education and that the applicant for medical care should not be exposed to the humiliation of demonstrating his economic dependency. There would seem nothing in the requirements of 'Title XIII to preclude so comprehensive a program from being developed.

At the hearings before the Subcommittee of the Senate Committee on Education and Labor, representatives of various schools of practitioners and of allied professions appeared to request specific provision for the participation of their services in the state plans. In its "Preliminary Report" the Subcommittee restated what was doubtless the intention of the draftsmen, namely, that this problem should be left to the discretion of the states in whose jurisdiction the licensing and regulation of the healing arts has always fallen. ${ }^{13}$ It seems probable that this solution of the problem would persist in any federal legislation which might be enacted.

The title does not influence the choice by the state of the method of remunerating physicians providing service under the plans. But new conditions may. Free choice of physician is an ideal which requires for its attainment a degree of professional co-

${ }^{13}$ See Prelim. Report, "Establishing a National Health Program," Subcomm. of Sen. Comm. on Education and Labor, S. Rep. No. I139, 76th Cong., Ist Sess. (1939) $35^{\circ}$ 
operation that may be difficult to secure and certainly to maintain throughout a state. On the other hand, the sounder financial basis for the new plans and their more efficient administration should result in a better salaried staff and in the supplementation of their services by the use of specialists and consultants and, when peak loads were encountered, general practitioners.

The development of satisfactory arrangements for hospital care under the plan contemplated by Title XIII seems relatively simple of achievement. ${ }^{14} \mathrm{It}$ is important in this connection to point out that this title contains an answer to criticisms raised by medical and hospital authorities concerning the failure of Title XII to provide aid to existing hospital facilities along with its provision for the constructon of new ones. A comprehensive and adequately financed system of public medical care would assure to existing non-governmental hospitals a considerable increase in the volume of patients at compensatory rates.

This observation of course presupposes sufficient appropriations. The title authorizes a federal appropriation of $\$ 35,000,000$ for the first year and thereafter of a sum "sufficient to carry out the purposes of this title."15 It is probable that the primary limiting factor will be the state rather than the federal appropriation. The limitation contained in the title that in computing the matching grant "so much of each total expenditures by the State and its political subdivisions as are. ... In excess of $\$ 20$ annually per individual eligible for medical care under such plan"16 will, it may be suspected, represent for many years to come more a counsel of perfection than a restriction.

Even if those states which were first to take advantage of the federal grants contemplated by Title XIII should not increase their total expenditures for medical care, the gain to the public medical services would certainly represent far more than the increment of federal money. To the extent that the findings of the American Public Welfare Association's committee are representative of public medical services, it seems inevitable that the establishment of plans in conformity to Title XIII's specifications would assure a far more efficient use of those dollars that are appropriated than is now the case. And the efficient administration of an appropriation affords the best basis for obtaining greater sums where these are needed to meet human needs.

\footnotetext{
14 $\mathrm{A}$ basis for the development of this aspect of state plans is already laid in a statement of principles devcloped by a joint committee of the American Hospital Association and the American Public Welfare Association on "Relations Between Public Authorities and Hospitals." The committee's statement is printed in Hospital Care for the Needy (1938) I2 Hospirsus, No. 8, p. 17.

${ }^{15}$ Nat. Health Bill, §1301.

${ }^{16}$ Ibid. See note II, supra.
} 